\title{
Polymer nano-rings with uranium specific clefts for selective recovery of uranium from acidic effluents via reductive adsorption
}

\author{
Shilpi Kushwaha, ${ }^{\mathrm{a}, \mathrm{b} *}$ Manoj Mane, ${ }^{\mathrm{c}}$ Sapna Ravindranathan,, ${ }^{\mathrm{a}, \mathrm{d}}$ and Amitava Das ${ }^{\mathrm{a}, e *}$

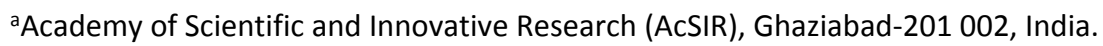 \\ ${ }^{b}$ Analytical and Environmental Sciences Division and Centralized Instrumentation Facility, CSIR-Central Salt and Marine \\ Chemicals Research Institute, Bhavnagar-364002, India. \\ 'KAUST Catalysis Centre, King Abdullah University of Science and Technology (KAUST), Thuwal 23955-900, Saudi Arabia. \\ ${ }^{\mathrm{d} C e n t r a l}$ NMR Facility, CSIR-National Chemical Laboratory, Pune-411008, India. \\ eIndian Institute of Science and Education and Research Kolkata, Department of Chemical Sciences, Mohanpur- 741246, West \\ Bengal, India.
}

Corresponding Author: shilpik@csmcri.res.in (S.K.), amitava@iiserkol.ac.in (A.D.)

Abstract: Nanostructured polymeric materials, functionalized with appropriate receptor have opened up newer possibilities for designing a reagent that shows analyte-specific recognition and efficient scavenging of an analyte that has either detrimental influence for human physiology and environment or for its recovery for further value addition. Higher active surface area, morphological diversity, synthetic tuneability for desired surface functionalization, and the ease of regeneration of nanostructured material for further use have provided such material with a distinct edge over conventional reagents. Use of biodegradable polymeric backbone has an added significance owing to the recent concern over the impact of polymer on the environment. Functionalization of biodegradable sodium alginate with AENA ( $6.85 \%$ grafting) as the receptor functionality led to a unique open framework nanoring (NNRG) morphology with a favourable spatial orientation for specific recognition and efficient binding to uranyl ions $(U)$ in an aqueous medium over a varied $\mathrm{pH}$ range. Nanoring morphology was confirmed by TEM and AFM images. The nano-scale design maximizes the surface area for the molecular scavenger. A combination of all these features along with the reversible binding phenomenon has made NNRG as a superior reagent for specific, efficient uptake of $\mathrm{UO}_{2}{ }^{2+}$ species from an acidic (pH 3-4) solution and compares better than all existing $\mathrm{UO}_{2}{ }^{2+}$-scavengers reported till date. This could be utilized for recovery of uranyl species from a synthetic acidic effluent of the nuclear power. Results of the $U$ uptake experiments reveal a maximum adsorption capacity of $\mathbf{2 6 8}$ $\mathrm{mg}$ of $U$ per $\mathrm{g}$ of NNRG in synthetic nuclear effluent. XPS studies revealed a reductive complexation process and stabilization of $\mathrm{U}(\mathrm{IV})$-species in adsorbed uranium species (U@NNRG).

Keywords: Uranium, Molecular recognition, Uranyl-specific receptor, Sodium alginate, Biodegradable polymeric backbone, Nanostructured material

Uranium is a well-known strategic resource of nuclear power that is crucial for sustainable low-carbon and clean energy production. Globally, 65,000 tonnes of uranium are required each year to cater to the need of the combined capacity of 400 Gwe for the world's power reactors. Despite certain uncertainty about the current consumption rates, it has been argued that the known geological reserves of uranium (5.7 million tonnes) may last for the next 90 years. ${ }^{1-4} \mathrm{~A}$ recent report from World Nuclear Association reveals that about $85 \%$ of the total nuclear fuel requirements are met from the primary supply, while the rest from secondary sources, which includes recycled uranium from reprocessing used fuel, and some from re-enrichment of depleted uranium tails. ${ }^{2}$ These various secondary sources make uranium unique among energy minerals and offer the scope for developing efficient and specific scavenger for uranium-species. ${ }^{5-9}$ Need for such a specific scavenger is further augmented due to the detrimental influences of different uranium-species on human physiology. ${ }^{10,11}$ Iniquitous incidents and other adversities like the malfunctioning of nuclear reactors (Three-mile Island, Chernobyl, Fukushima) have contributed significantly to the presence of various uranium-species in environmental samples. ${ }^{3,4}$ Uranium mostly exists as $\mathrm{UO}_{2}{ }^{2+}$ in environmental samples owing to its high mobility in groundwater ${ }^{12}$ and shows chemotoxicity as well as radiotoxicity towards human physiology. Literature reports suggest that $\mathrm{UO}_{2}{ }^{2+}$ lead to irreversible kidney damage, urinary system disease, DNA damage, or the disruption of biomolecules. ${ }^{10,11}$ All these confirm the scope for developing a reagent that can specifically recognize and effectively scavenge $\mathrm{UO}_{2}{ }^{2+}$ species in environmental samples.

Literature reports argue in favour of adsorption based scavenging material as the preferred methodology for $\mathrm{UO}_{2}{ }^{2+}$ extraction and enrichment, rather than solvent extraction based processes. ${ }^{13-15}$ Based on the higher affinity of $\mathrm{UO}_{2}{ }^{2+}$, adsorbents are typically derived using amidoxime, amide, imidazole, organophosphorus, and calixarene, phosphonic acid/ phosphazene derivatives for developing reasonably efficient scavenger for $\mathrm{UO}_{2}{ }^{2+} \cdot{ }^{13-48}$ Such efforts include the use of appropriately functionalized porous-organic polymers/ COFs, 
mesoporous carbons, nano-structured or MOF-based materials. ${ }^{5,49-56}$ Long equilibration time, uncertainty about the influences of nano-particle on human physiology and the recent environmental concern of the treated organic/ inorganicpolymeric materials have limited use of these reagents/ materials for any practical application. Further, the use of any scavenger having a biodegradable polymer has rarely been attempted. Tripathi and Melo reported $240 \mathrm{mg} / \mathrm{g}$ uranium adsorption at $\mathrm{pH} 5.5$ using a composite matrix of biopolymers (i.e., agarose and alginate). ${ }^{57,58}$ All these reports clearly emphasize the scope for an efficient $\mathrm{UO}_{2}{ }^{2+}$ scavenger using a biodegradable scalp hold. To address this issue, we have utilized a modified alginate backbone with favourable spatial orientations for nitrogen and oxygen donors for efficient binding and improved extraction of $\mathrm{UO}_{2}{ }^{2+}$ from synthetic nuclear reactor effluent and such examples are scarce in contemporary literature. Various physicochemical and spectroscopic studies could help us in developing insight about the binding process and confirm that reductive adsorption of $\mathrm{U}$ species happens during the complex formation between $U$ and NNRG.

\section{RESULTS AND DISCUSSION}

\section{Receptor design}

The functionalization of the alginate backbone with a naphthalic anhydride derivative (AENA; with $6.85 \%$ grafting) helps in attaining an open framework nano-ring morphology (NNRG) with appropriate spatial orientation of the metal-ion coordinating functionalities. This helps to adopt the receptor groove a unique selectivity towards $\mathrm{UO}_{2}{ }^{2+}$ ions. This open framework architecture of NNRG provides a permeable network which allows faster diffusion of ions through the adsorbent. Favourable $\mathrm{pK}_{\mathrm{a}}$ (coo-) of $\sim 3.5$ makes NNRG suitable for adsorption in acidic $\mathrm{pH}$ above $\mathrm{pk}_{\mathrm{a}}$ value. ${ }^{59}$ Additionally, the $\pi$-electron cloud of conjugated AENA forms an electrical double layer with Debye thickness $\left(\lambda_{D}\right)<1 \mathrm{~nm}$ and helps in localizing the counterions in the vicinity of the binding site. Other competing ions failed to influence the specificity of NNRG towards uranyl species. The open framework feature of NNRG helps in faster detection and extraction of $U$ from complex aqueous matrix such as nuclear effluent.

\section{Preparation and characterization of NNRG}

Surface functionalization of the low-cost naturally available biopolymer, sodium alginate (Alg) was achieved by covalent coupling of the - $\mathrm{COOH}$ functionalities of Alg with presynthesized 2-(2-aminoethyl)-1H-benzo[de]isoquinoline$1,3(2 \mathrm{H})$-dione (AENA) through the formation of amide derivative. Unreacted AENA was removed further by dialysis to yield the polymeric nano-rings of AENA functionalized Alg (AA). The degree of grafting AENA on alginate backbone was evaluated as $6.85 \%(\mathrm{w} / \mathrm{w})$ (Table $\mathrm{S} 1) .{ }^{60}$ An aromatic moiety of cross-linked AENA imparts certain hydrophobicity to the hydrophilic alginate chains, which helped in the self-assembly process for adopting the nano-rings structure (vide infra) for AA. Self-assembled NNRG was visualized with the help of TEM images (Figure 1).

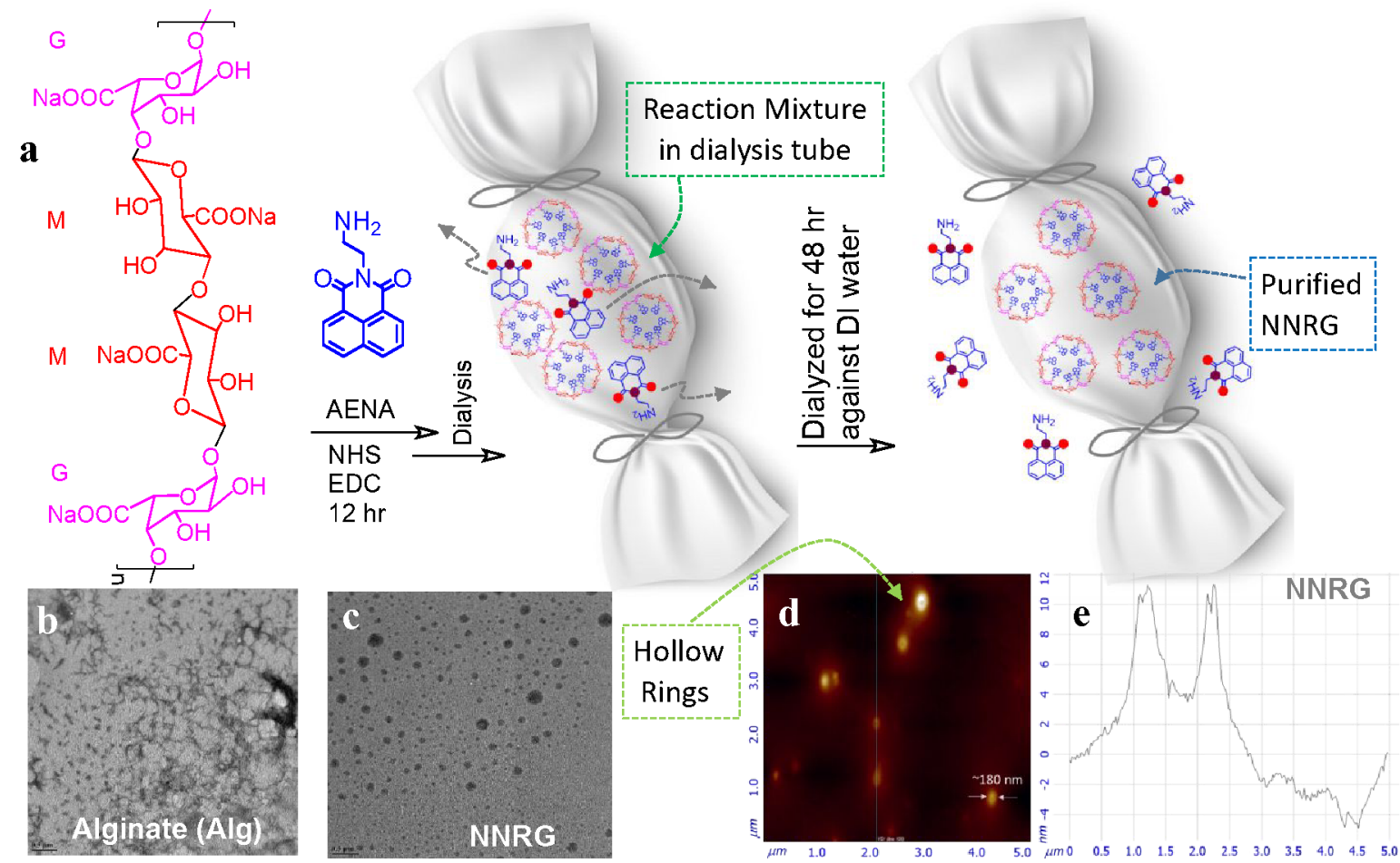

Figure 1. (a) Synthetic methodology adopted for the functionalization of Alginate backbone and cartoon representation for the purification of NNRG through dialysis; TEM images of (b) Alg and (c) NNRG at $0.5 \mathrm{~mm}$ scale and (d) two-dimensional atomic force micrograph of NNRG with (e) depth profile. 
Alg showed the usual fibrous morphology of the polymer, which changed upon cross-linking with AENA, and resulted in the formation of a core-shell type of self-assembled nano-rings of AA in aqueous solution (vide infra). Importantly, no further usages of another homopolymer, copolymer, or surfactant were required for the generation of such a nano-ring structure. Covalent linking of AENA and Alg for the generation of NNRG through amide bond formation was studied using the vibrational spectroscopy (Figure $2(1)$ ). Distinct shifts for the $\mathrm{OH} / \mathrm{NH}$ stretching frequencies $\left(\sim 3401 \mathrm{~cm}^{-1}\right.$ for Alginate, 3456 $\mathrm{cm}^{-1}$ for AENA and $3428 \mathrm{~cm}^{-1}$ for NNRG) were evident and such changes supported the modification of alginate moiety. ${ }^{57-63} \mathrm{~A}$ strong band at $1609 \mathrm{~cm}^{-1}$ was attributed to the $\mathrm{C}=0$ stretching for $\mathrm{COO}^{-}{ }_{\text {Alginate. }}{ }^{62,63}$ Bands at $1662 \mathrm{~cm}^{-1} \& 1614 \mathrm{~cm}^{-1}$ were assigned to $\mathrm{C}=\mathrm{O}$ stretching of anhydride functionality and $\mathrm{N}-\mathrm{H}$ bending of amine in AENA, respectively. Upon the formation of NNRG, a small shoulder was evident at $1662 \mathrm{~cm}^{-1}$ ($\mathrm{RCONR}^{\prime}{ }_{\text {Anhydride) }}$ ) and an intense signal was observed at $1614 \mathrm{~cm}^{-1}$ $\left(-\mathrm{CONHR}_{\text {Amide }}\right)$, which ascertained the formation of RCONHR' $\left(\mathrm{R}=\right.$ Alg and $\left.\mathrm{R}^{\prime}=\mathrm{AENA}\right){ }^{61}$ Sharp peaks at $1384 \mathrm{~cm}^{-1}$ (overtone of amide), and $1463 \mathrm{~cm}^{-1}$ (aromatic $-\mathrm{C}=\mathrm{C}$ - stretching) were present in AENA, as well as in NNRG. ${ }^{61-63} \mathrm{~A}$ band at $1275 \mathrm{~cm}^{-1}$ ($\mathrm{NH}$ stretching) corresponds to the primary amine of AENA, which was absent for NNRG suggesting the alteration of primary amine. 61-63 While the peaks at $1151 \mathrm{~cm}^{-1}(\mathrm{C}-\mathrm{O}$ stretching vibrations in $\mathrm{C}-\mathrm{O}-\mathrm{C}$ glycosidic linkages $), 1081 \mathrm{~cm}^{-1}\left(\mathrm{C}_{1}-\mathrm{H}\right.$ bending vibration in sugars), and $1028 \mathrm{~cm}^{-1}(\mathrm{C}-\mathrm{OH}$ for $\mathrm{COOH}$ /glucose residue of disaccharides) in Alg remained intact in
NNRG. ${ }^{61-63}$ These results confirmed the formation of RCONHR' $\left(R=A l g\right.$ and $\left.R^{\prime}=A E N A\right)$.

A close look at the results of the NMR spectral studies revealed that the aromatic protons $\left(H_{b}, H_{c}\right)$ and methylene protons $\left(H_{d}\right)$ were slightly shielded in NNRG (Figure 2, Figure S1 to S6). Figure 2 (III) inset spectrum was recorded with the selective excitation of the aromatic region in NNRG to elucidate the signal for the bound AENA. Presumably, ring formation and the microenvironment inside the ring influenced secondary interactions and could also be contributing towards the observed up-field shifts. Functionalization of Alg was ascertained by observing correlation in two-dimensional correlation spectroscopy (COSY) and heteronuclear single quantum coherence (HSQC) between aromatic protons of AENA fragments and alginate sugars (see Figure S7 \& S8). NMR diffusion coefficient measurements (Figure S9) revealed that aromatic signals were not completely attenuated even with $\sim 95 \%$ applied gradient strength, which further approved the chemical cross-linking of AENA in NNRG.

Nano morphology for NNRG (diameter $180 \mathrm{~nm}$ ) was ensured based on the transmission electron (Figure 1c) and atomic force (Figure 1d, 1e) microscopic studies. In transmission electron microscopy (TEM), the interaction of the high energy electron beam with organic NNRG results in electron beam damage at the focal point and this was the limiting factor for acquisition of hollow-ring structure with high spatial resolution. Further for our confirmation, upon instantaneous $U$ binding, clear ring morphology is seen in TEM images (vide infra). AFM images (Figure $1 \mathrm{~d}$ and 1e) confirm the nano-ring morphology for NNRG.

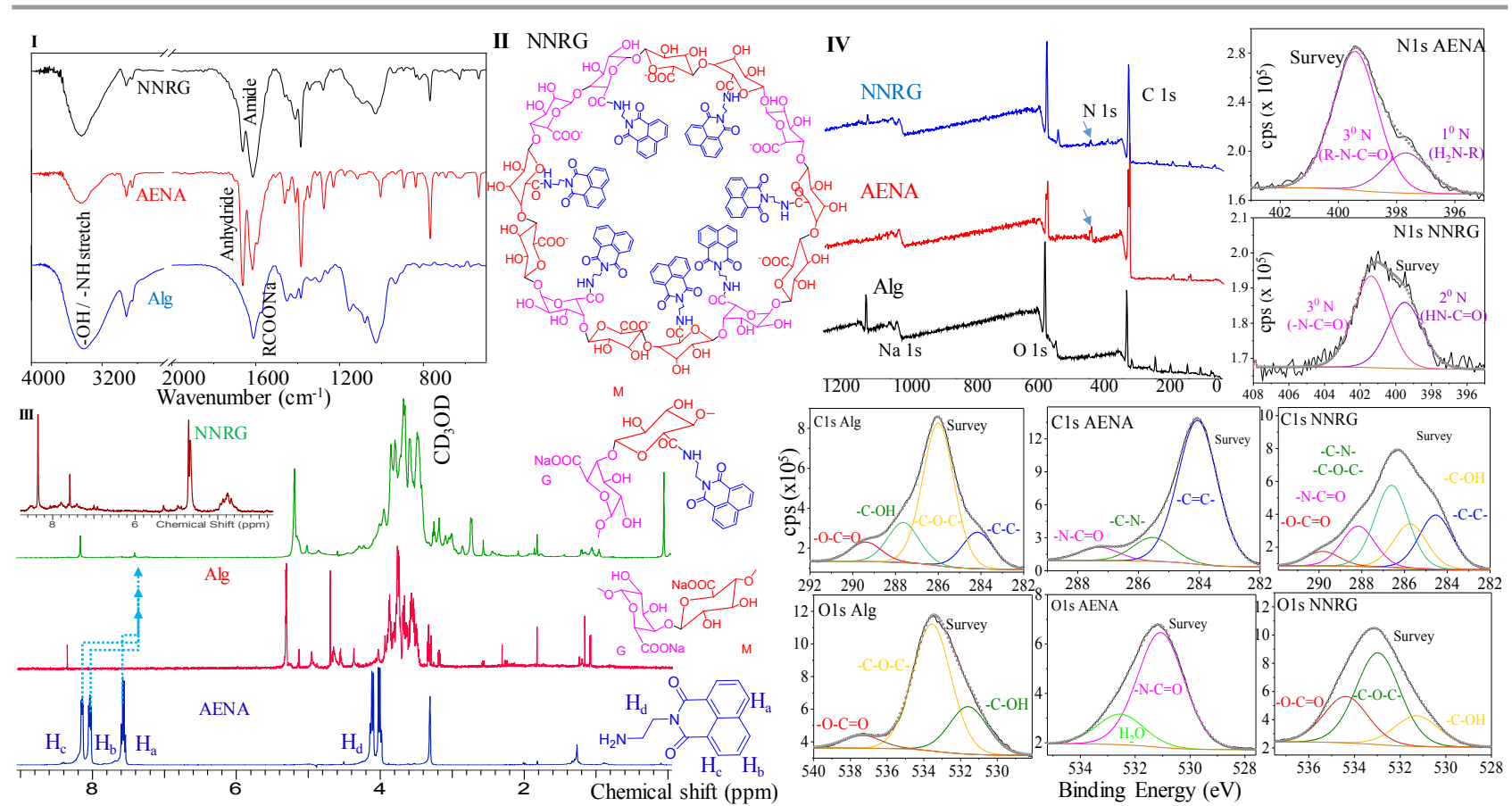

Figure 2. Characterization of functionalization of alginate with AENA and formation of NNRG, (I) FTIR spectra for alginate, AENA and NNRG, (II) proposed arrangement of NNRG, (III) NMR spectra, and (IV) Widescan XPS spectra, High resultion N1s, C1s and O1s spectra for alginate, AENA and NNRG 
X-ray photoelectron Spectroscopic (XPS) studies were performed for defining the quantitative composition of NNRG and its bonding pattern. The wide scan spectra along with highresolution spectra with appropriate assignments for the respective atom are shown in Figure 2 (IV). Detailed description and assignments are also presented in the supporting information for better clarity. These results confirmed the amide bond formation between the carboxylate functionality of the alginate and the amine functionality of the AENA moieties. The attributed to the decrease in binding energy for the respective atom due to the shift in electron density from oxygen to nitrogen for the amide bond formation and confirmed our proposition on the amide bond formation in NNRG.

\section{Adsorption of Uranium on NNRG}

\section{Effect of initial conditions on uptake of $U$ using NNRG}

Adsorption of $U$ by NNRG was calculated by monitoring the residual concentration in the solution using standard ICP-OES method and details are provided in SI. The amount of NNRG dose required for the maximum uptake of $U$ from its aqueous solutions was studied with varied doses of NNRG (0.2 to $2.0 \mathrm{~g} / \mathrm{L})$ to a solution with fixed $\mathrm{U}$ concentration (1 $\mathrm{mM}$ uranium). A sharp increase in uptake capacity of $U$ ( $22 \%$ to $>95 \%$ uptake) was observed with an increasing dose of NNRG, till a plateau was attained at NNRG dose of $1 \mathrm{~g} / \mathrm{L}$ due to the saturation of adsorbent (Figure 3a, blue line). Whereas, the plot for $U$ adsorbed per gram of NNRG as a function of NNRG (adsorbent) dose in $\mathrm{mg} / \mathrm{g}$ (Figure 3a, black line) at fixed $1 \mathrm{mM} \mathrm{U}$ initial concentration, shows an initial plateau for adsorbent dose up to $1 \mathrm{~g} / \mathrm{L}$ followed by a sudden decrease upon increasing the adsorbent dose beyond $1 \mathrm{~g} / \mathrm{L} .{ }^{59,63-68}$ The inflexion point in Figure 3 a reveals that $1 \mathrm{~g} / \mathrm{LNNRG}$ is sufficient for efficient adsorption of $1 \mathrm{mM}$ of the initial concentration of $\mathrm{U}$. This ratio $(1 \mathrm{~g} / \mathrm{L}$ of NNRG) was maintained for farther experiments.

The influence of $\mathrm{pH}$ was studied over a range of 1 to 10 while maintaining the $U$ concentration at $1 \mathrm{mM}$ in aqueous solution
(Figure 3b). For unmodified Alg, an uptake of $\sim 85 \mathrm{mg} \mathrm{U} / \mathrm{g}$ of Alg was observed. Compared to this, the enhanced adsorption capacity of 225 to $238 \mathrm{mg}$ of U/g of NNRG (> 95\% uptake) over a broad $\mathrm{pH}$ range $\mathrm{pH} 3-\mathrm{pH} 9$ was observed and the most efficient uptake was observed over a $\mathrm{pH}$ range of 4-6. This enhanced adsorption for NNRG was attributed to the cleft created by the cross-linking of AENA, which provided the additional chelating ability to NNRG. Within these NNRG, Natoms of the RCONHR', and O-atoms of the hydroxyl/ unreacted $-\mathrm{COOH}$ groups adopted favourable spatial orientations for efficient binding to $\mathrm{U}$. A maximum adsorption of $238 \mathrm{mg} \mathrm{U} / \mathrm{g}$ of NNRG ( 99\% uptake) was observed at $\mathrm{pH} 4$ and this was important for Uranium recovery studies from acidic nuclear effluents. Figure $3 c$ reveals the variation of $q_{\mathrm{e}}$ (amount of $U$ adsorbed in $\mathrm{mg} / \mathrm{g}$ onto NNRG, refer $\mathrm{SI} \mathrm{Eq} 3$ ) as a function of time and this ensures that the effective binding happens within 30 minutes of incubation time. A linear relation was observed for the $\ln K_{\mathrm{d}}$ vs. $1 / \mathrm{T}$ plot (Figure $3 \mathrm{~d}$ ).

\section{Isotherms for uranium adsorption}

Adsorption experiments (Figure 3e) reveals rapid uptake $>97 \%$ within $30 \mathrm{mins}$, during the initial range of uranium concentration ( $\leq 1 \mathrm{mM}$ with $q_{\mathrm{e}}=230 \mathrm{mg} / \mathrm{g}$ ). Further increase in the initial $\mathrm{U}$ concentration to $10 \mathrm{mM}$, a decrease in the uptake from $89 \%$ to $12 \%$ was observed with a minimal increase in adsorption capacity from $q_{\mathrm{e}}=230 \mathrm{mg} / \mathrm{g}$ to $265 \mathrm{mg} / \mathrm{g}$. This suggested saturation of active binding sites in NNRG that were available for adsorption. The analysis of adsorption processes using two and three-parameter isotherm models (SI section, and Figure S10) helped us understanding the underlying mechanisms responsible for adsorption equilibrium. ${ }^{64,65}$ Better correlation coefficient $r^{2}=0.991$ for the Langmuir model (Figure 3f) supported our hypothesis that uranyl molecules were diffused through the NNRG and allowed monolayer adsorption on the finite number of identical sites of NNRG. $.5,67,70$
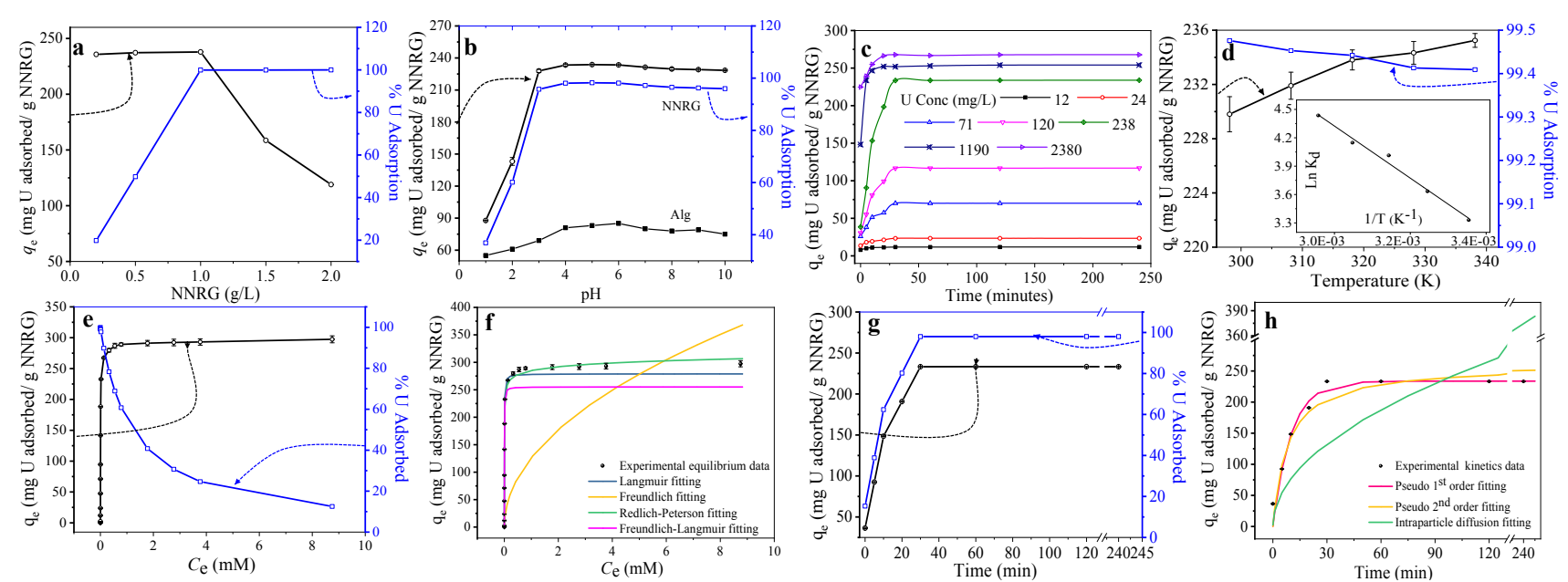

Figure 3. Adsorption experiments for uranium on NNRG for (a) adsorbent dose variation; (b) pH variation; (c) time variation for varied initial $U$ concentration; (d) temperature variation; with fixed parameters as $1 \mathrm{mM}$ initial concentration of $\mathrm{U}, \mathrm{pH} 4,1 \mathrm{~g} / \mathrm{L}, 30$ mins, $25^{\circ} \mathrm{C}$; (e) Isotherm experiments with varied initial concentration of uranium $\left(1 \mu \mathrm{M}\right.$ to $10 \mathrm{mM}$ ) at pH 4, $1 \mathrm{~g} / \mathrm{L}, 30 \mathrm{mins}, 25^{\circ} \mathrm{C}$; ( $\mathrm{f}$ ) Adsorption isotherm models fitted to the initial concentration variation experiment data; (g) Contact time variation (upto 240 mins), with fixed parameters as $1 \mathrm{mM}$ initial concentration of $\mathrm{U}, \mathrm{pH} 4,1 \mathrm{~g} / \mathrm{L} \mathrm{NNRG,} 25^{\circ} \mathrm{C}$; (h) Fitting of adsorption kinetic models to the contact time variation experimental data 
Freundlich model with poor correlation coefficient $r^{2}=0.514$ (Figure 3f), further confirmed that multilayer adsorption was not happening. Sips model (Langmuir-Freundlich model) with moderate fitting and evaluated value of $n=1.03$ suggested adsorption of $\sim 1$ uranyl molecule per free adsorbent site (Figure 3f). ${ }^{65,70}$ Experimental adsorption isotherm data is best fitted to the Redlich-Peterson model $\left(r^{2}=0.996\right)$, which is an empirical combination of the Langmuir and Freundlich equations.

The Redlich-Peterson equilibrium constant $6 \cong 1.0$ suggested the Langmuir type monolayer adsorption with a hybrid of homogeneous and heterogeneous adsorbent surface. ${ }^{65}$ The maximum adsorption capacity calculated from the Langmuir and Redlich-Peterson models was $278 \mathrm{mg} / \mathrm{g}$ and $342 \mathrm{mg} / \mathrm{g}$, respectively, in acidic $(\mathrm{pH}=4)$ uranium solution, which was in accordance with the maximum adsorption capacity at saturation $297 \mathrm{mg} / \mathrm{g}$ of NNRG.

\section{Kinetics of uranium adsorption}

To investigate the mechanism and potential rate-controlling steps associated with the dynamics of the efficient adsorption process, necessary kinetic studies were performed and experimental data were fitted to various kinetic models (Figure $3 \mathrm{~g} \& 3 \mathrm{~h}$ ). The non-linear as well as linear (Figure S11) fitting to the adsorption kinetics models, pseudo $1^{\text {st }}$ order kinetics (pK1) and pseudo $2^{\text {nd }}$ order kinetics (pK2) provided very good correlation with the experimental data (SI section 7). The adsorption capacities were calculated for pK1 is $q_{\mathrm{e}}=233.7$ $\mathrm{mg} / \mathrm{g}$, and pK2 is $q_{\mathrm{e}}=259.4 \mathrm{mg} / \mathrm{g}$, achieved with the non-linearly fitted kinetic models. However, linear fitting provides an underestimation of adsorption capacity for both the adsorption models (pK1 $q_{\mathrm{e}}=224.43 \mathrm{mg} / \mathrm{g} ; \mathrm{pK} 2 q_{\mathrm{e}}=237.5 \mathrm{mg} / \mathrm{g}$ ). ${ }^{71}$

The discrepancies here in pK1 fitted $q_{\mathrm{e}}(233.7 \mathrm{mg} / \mathrm{g})$ and $q_{\mathrm{e}(\exp )}$ $(297 \mathrm{mg} / \mathrm{g})$, shows an underestimation of binding sites, suggesting the rate of reaction is not diffusion controlled and adsorption here cannot be classified as truly pseudo $1^{\text {st }}$ order. ${ }^{67}$ 70,71 Whereas, the adsorption capacity obtained from pK2 fitting $q_{\mathrm{e}}=259.4 \mathrm{mg} / \mathrm{g}$ is relatively closer to the true adsorption capacity at equilibrium $(297 \mathrm{mg} / \mathrm{g})$. The adsorption is driven by the pseudo $2^{\text {nd }}$ order kinetics and the rate limiting step in attaining the equilibrium is chemisorption involving the valence forces through the exchange of electrons between NNRG and $\mathrm{U}$, complexation, coordination and/or chelation. ${ }^{69,74}$

\section{Adsorption Thermodynamics}

Adsorption thermodynamics was observed to study the change in the energetics of the adsorption. ${ }^{19}$ Thermodynamic parameters of the adsorption process $\left(\Delta \mathrm{G}^{0}, \Delta \mathrm{H}^{0}, \Delta \mathrm{S}^{\circ}\right)$ were determined from the adsorption experiments conducted at various temperatures (Figure $3 \mathrm{~d}$ ) using standard equations, where $K_{\mathrm{d}}(\mathrm{ml} / \mathrm{g})$ is the distribution coefficient and is expressed as $q_{\mathrm{e}} / C_{\mathrm{e}}$. The distribution coefficient $\left(K_{\mathrm{d}}\right)$ was evaluated as 2.79 $x 10^{4}$ at $25{ }^{\circ} \mathrm{C}$ and this signified an excellent affinity of NNRG towards U-species (Table S2). The Gibbs free energy of -71 $\mathrm{kJ} / \mathrm{mol}$ was evaluated for the adsorption of uranium at room temperature. This signified little increase in adsorption with an increase in temperature. Negative enthalpy $-22.91 \mathrm{~kJ} / \mathrm{mol}$ and positive entropy $0.16 \mathrm{~kJ} / \mathrm{mol} / \mathrm{K}$ also supported the feasibility and spontaneity of the adsorption process.

\section{Selective adsorption of $U$}

To investigate the influence of other possible competing metal ions on selective extraction, $1 \mathrm{~g} / \mathrm{L}$ adsorbent (NNRG) was dispersed into $10 \mathrm{mM}$ of competing metal ions $\mathrm{M}\left(\mathrm{NO}_{3}\right) \mathrm{x} \cdot \mathrm{n}\left(\mathrm{H}_{2} \mathrm{O}\right)$ $(\mathrm{M}=\mathrm{Li}, \mathrm{Na}, \mathrm{K}, \mathrm{Cs}, \mathrm{Mg}, \mathrm{Ca}, \mathrm{Ba}, \mathrm{Cr}, \mathrm{Fe}, \mathrm{Co}, \mathrm{Ni}, \mathrm{Cu}, \mathrm{Zn}, \mathrm{Cd}, \mathrm{Hg}, \mathrm{Pb}$, $\mathrm{Ce}, \mathrm{Yb}, \mathrm{Y}, \mathrm{Tm}, \mathrm{Ho}, \mathrm{Pr}, \mathrm{Lu}, \mathrm{Eu}, \mathrm{Dy}, \mathrm{Nd}, \mathrm{Er}, \mathrm{La}, \mathrm{Th}$ and $\mathrm{U}$ ) in an aqueous solution having $\mathrm{pH} 4$ at $25^{\circ} \mathrm{C}$.

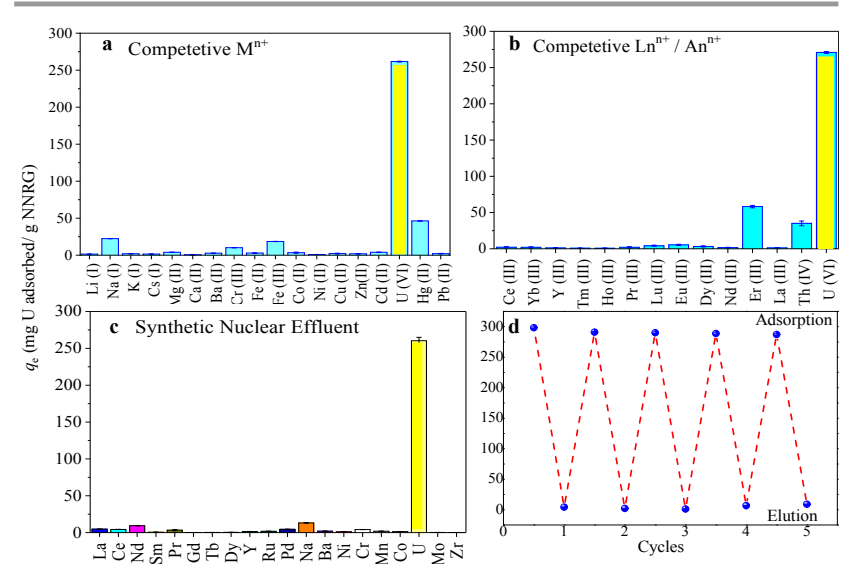

Figure 4. Adsorption experiments for uranium adsorption onto NNRG from (a $\&$ b) presence of various competing ions, (c) synthetic nuclear effluent (d)

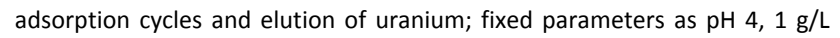
NNRG, $30 \mathrm{mins}, 25^{\circ} \mathrm{C}, 10 \mathrm{mM}$ initial concentration of $\mathrm{U}$

Higher values for the distribution coefficient $K_{d}$ suggest excellent binding affinity of $U$ to the NNRG (Figure $S$ 12). The sampling solutions were filtered with a $0.22 \mu \mathrm{m}$ nylon membrane filter and the respective concentration of uranium was estimated by ICP-OES. This also helped us in evaluating the remaining concentration of uranium in the solution. Selective uptake of uranium by NNRG was observed for most of the metal ions studied; barring certain interference from $\mathrm{Hg}$, $\mathrm{Th}$, and $\mathrm{Er}$ (Figures $4 a \& 4 b$ ). The maximum adsorption capacities of NNRG for uranium $(\sim 268 \mathrm{mg} / \mathrm{g})$ at $\mathrm{pH} 4.0$ were also evaluated in presence of other competing ions and this value was comparable to the maximum adsorption capacity at saturation $297 \mathrm{mg} / \mathrm{g}$ calculated in an earlier section (vide infra). This confirmed a negligible influence of competing ions on the selectivity of NNRG towards uranium ion.

\section{Removal of $U$ from Synthetic Nuclear Power Reactor Effluents}

The synthetic nuclear power reactor effluent was prepared following the literature procedure and media $\mathrm{pH}$ was maintained at $~ 4.0$ (Tabl S3). ${ }^{75}$ NNRG $(1 \mathrm{~g} / \mathrm{L})$ was added to the synthetic effluent sample and stirred for $30 \mathrm{~min}$, then solutions were filtered using a $0.22 \mu \mathrm{m}$ nylon membrane filter and the respective concentration of uranium was measured by ICP-OES for evaluation of the residual concentration of uranium in the solution. The batch experiment showed classic adsorption of uranium from the synthetic nuclear effluent with an adsorption capacity of $268 \mathrm{mg} \mathrm{U} / \mathrm{g}$ of NNRG (Figure 4c). Adsorption of other 
metals in synthetic nuclear effluents was also tested and was found to be minimal. Presumably, the appropriate grooves/ cavity aperture in NNRG was the auxiliary benefit for achieving the desired specificity towards $U$.

\section{Desorption of $U$ and regeneration of NNRG}

Recovery of adsorbed uranium and regeneration of the NNRG was examined. Desorption of uranium and regeneration of the NNRG were studied through five successive adsorptiondesorption cycles. Uranium adsorbed NNRG (U@NNRG) was obtained by dispersing, $10 \mathrm{mg}$ of NNRG into $10 \mathrm{~mL}$ of $10 \mathrm{mM}$ aqueous uranium solution and stirred for approximately $30 \mathrm{~min}$ at room temperature. U@NNRG was separated from the solution by centrifugation and was washed with water (having $\mathrm{pH}$ 4.0) before it was air dried. For desorption studies, this predried U@NNRG powder was dispersed in $10 \mathrm{ml}$ of $10 \mathrm{mM}$ $\mathrm{HCl}$ solution. Facile and fast desorption ( $\sim 5$ minutes) for the regeneration of NNRG from U@NNRG (Figure S 13) was achieved. This desorbed solution was filtered with a $0.22 \mu \mathrm{m}$ nylon membrane filter and the concentrations of the respective uranium (desorbed) were estimated by ICP-OES. The maximum adsorption capacities of uranium by NNRG was found to change from 298 to $287 \mathrm{mg}$ uranium / g of NNRG at the end of the fifth cycle. A little higher value for the extent of uranium desorbed in the third cycle could be attributed to the release of the residual adsorbed $U$ in follow-up elution cycle (Figure 4d). Mass loss during the adsorption/desorption process could have also contributed to the slight decrease in the maximum adsorption. These findings confirmed that NNRG showed good recoverability and recyclability for the removal of $U$ in environmental remediation.

\section{Mechanism of $U$ adsorption}

Uranium adsorption and desorption on NNRG were also studied using various spectroscopic (FTIR, NMR, XPS, NMR, Steady-state emission) and morphological analyses (Figure 5). The FTIR spectra recorded for U@NNRG (Figure 5(I)) showed the shifting of the $\mathrm{C}=\mathrm{O}$ stretching band $\left(-\mathrm{RCONR}_{2}{ }_{2}\right.$ ) from $1662 \mathrm{~cm}^{-1}$ (NNRG) $\rightarrow 1655 \mathrm{~cm}^{-1}$ (U@NNRG). ${ }^{61}$ This could be attributed to the decrease in electron density on binding to $\mathrm{UO}_{2}{ }^{2+}$ centres and this further signified the metal coordination through anhydride oxygen.

The $\mathrm{C}-\mathrm{O}$ stretching vibration corresponding to the $\mathrm{C} 4-\mathrm{OH} / \mathrm{R}$ $\mathrm{COOH}$ was found to shift from $1028 \mathrm{~cm}^{-1}$ (Alg) $\rightarrow 1033 \mathrm{~cm}^{-1}$ (U@NNRG) and this confirmed $\mathrm{UO}_{2}$-coordination through

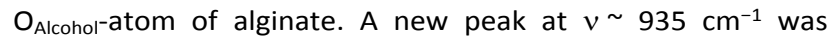
observed for U@NNRG and was assigned to the asymmetric stretching vibration of $\mathrm{UO}_{2} \cdot{ }^{57-59}$ This ascertained that the uranium adsorption occurred by chemical adsorption of uranyl species. Further uranium complexation with NNRG was also ascertained from the NMR spectrum (Figure 5 (III)). Considerable shifts were observed for aromatic protons upon complexation with uranium species.

XPS analyses were performed to explore the binding mechanism associated with the adsorption of uranium to NNRG. The wide scan XPS survey spectrum (Figure 5 (IVa)) revealed the presence of new U4f peaks in U@NNRG. The high resolution XPS spectra (U4f) of NNRG and U@NNRG (U adsorbed at $\mathrm{pH}$ 4) (Figure 5 (IVb)) showed new bands at $~ 381.8$ and $392.5 \mathrm{eV}$. These were attributed to the characteristic doublets of $U 4 f 5 / 2$ and $U 4 f 7 / 2$, respectively. The $U 4 f 7 / 2$ and $\mathrm{U} 4 \mathrm{f5} / 2$ peaks were deconvoluted into three non-stoichiometric peaks, each due to different chemical environments on a Shirley background (Table S3). The chemical shift in the $U 4 \mathrm{f} 7 / 2$ peak position was directly related to the oxidation state of uranium, which suggested that U@NNRG had a mixture of U(VI), U(V), and $U(I V)$ oxidation states as shown in Figure 5 (IV). ${ }^{59}$ Binding energy is known to decrease as the oxidation state decreases from VI to IV. The $4 \mathrm{f}$ peak separation was found to be $\sim 10-11$ eV for each oxidation state of uranium in U@NNRG (Table S3). However, satellite peaks appeared at a few $\mathrm{eV}$ higher than the normal BE for both the $U 4 \mathrm{f} 7 / 2$ and the $U 4 \mathrm{f} 5 / 2$ peaks. Since the spin-orbit interaction separates these two levels by $10.85 \mathrm{eV}$, the satellites of $4 \mathrm{f} 7 / 2$ (which generally appear in this energy range) are presumably buried inside the intense $4 f 5 / 2$ peak. These satellite peaks carry the valence band information and are a good probe to identify chemical state and understand the chemical interaction. ${ }^{59}$

In U@NNRG, binding energies were found to shift for C1s spectra (Figure S14) of NNRG: all the five deconvoluted peaks that correspond to $-\mathrm{C}-\mathrm{C}$ - and $-\mathrm{C}=\mathrm{C}-\left(\right.$ peak $1,283.89 \mathrm{eV}$ ) of $\mathrm{sp}^{3}$ and $\mathrm{sp}^{2}$ carbon of alkyl chains and benzene rings, $-\mathrm{C}-\mathrm{OH}$ (peak 2 , $285.27 \mathrm{eV}$ ) alcoholic carbons, -C-N/ -C-O-C- (peak 3, $286.25 \mathrm{eV}$ ) carbon singly bonded to nitrogen/ oxygen, $-\mathrm{N}-\mathrm{C}=\mathrm{O}$ (peak 4 , $287.95 \mathrm{eV}$ ) carbon atom attached to a nitrogen and oxygen in an amide, and $-\mathrm{O}-\mathrm{C}=\mathrm{O}$ (peak 5, $289.09 \mathrm{eV}$ ) carbon atoms doubly attached to oxygen atoms of RCOOR' in NNRG. Likewise, deconvolution analysis of the $\mathrm{O} 1 \mathrm{~s}$ spectrum revealed that after binding to $\mathrm{U}(\mathrm{VI})$ (Figure $\mathrm{S} 14$ ), only the $\mathrm{O}=\mathrm{C}-\mathrm{O}$ signal shifted to the higher binding energy of $\sim 536.4 \mathrm{eV}$ and this suggested complexation to $\mathrm{U}(\mathrm{VI})$ by sharing electrons for the formation of $\mathrm{U}-\mathrm{O}$ bonds.

Upon uranium adsorption onto NNRG, N1s binding energy peaks were found to be shifted (399.5 $\rightarrow 400.1 \mathrm{eV}$ ) for $2^{0}$ (secondary) and $3^{\circ}$ (tertiary) $\mathrm{N}$-atom of RCONHR' and (401.4 $\rightarrow$ $402.6 \mathrm{eV}$ ) for $-\mathrm{N}-\mathrm{C}=\mathrm{O}$ of anhydride. The shift towards higher binding energy was observed in the N1s spectrum and this approved the complexation induced change in electron densities. Thus, the results of the XPS analyses confirmed that the uranium complexation followed the reductive adsorption of uranium. Possible binding modes for $\mathrm{U}(\mathrm{VI})$ and $\mathrm{U}(\mathrm{IV})$ species are shown in Figure S19, which were generated using simulation dynamics with Gaussian 09 programs.

Importantly, the appearance of the modified band at $420 \mathrm{~nm}$ in U@NNRG, corresponds to the characteristic emission of $\mathrm{U}^{4+}$, which is can be ascribed to the $6 \mathrm{~d} \rightarrow 5 \mathrm{f}$ transition. ${ }^{76}$ Uranium has characteristics fluorescence, which at room temperature gets quenched in aqueous solutions. Whereas in this case, cleft in the NNRG provides a hydrophobic environment with multidenticity which satisfies the coordination sphere of uranyl ion and replaces the complexed water molecules from its solvation sphere. This attributed to a turn on emission response in U@NNRG. The relative quantum yield of uranium at U@NNRG at $420 \mathrm{~nm}$ was determined to be high (75.48\%; quinine sulphate was used as the standard) (Figure S15). 


\section{Conclusions}

In this work, we successfully establish the grafting of alginate backbone with AENA functionality to create a nanoring structure (NNRG) with a favourable spatial orientation of the Oand $\mathrm{N}$ - atoms for efficient binding to Uranyl centre. The formation of NNRG is confirmed from the results of a combination of spectroscopic and microscopic studies. NNRG, the amide based extractant is found to be an efficient reagent for recovery of $U$ from acidic $\mathrm{pH}$ and eventually synthetic nuclear effluent. The adsorption capacity of NNRG for uranium is found to be 297 and $260 \mathrm{mg} \mathrm{U} / \mathrm{g}$ NNRG from aqueous solutions and synthetic nuclear effluent, respectively, and is comparable to the best-reported scavenger reagent for $\mathrm{UO}_{2}{ }^{2+}$. Adsorption phenomenon follows the Redlich-Peterson model suggesting monolayer adsorption on a hybrid homogeneous and heterogeneous adsorbent surface with a maximum adsorption capacity of $342 \mathrm{mg} \mathrm{U} / \mathrm{g}$ NNRG. Adsorption kinetics followed pseudo $1^{\text {st }}$ order model defining rapid adsorption within 30 mins as the rate limiting step, whereas moderate fitting to the pseudo $2^{\text {nd }}$ order model indicates that the

equilibrium is achieved by chemisorption. The spectroscopic investigation leads to the adsorption mechanism, which follows the reductive complexation of uranium with NNRG. More importantly, during reductive complexation, $U$ gets stabilized in its reduced form $\left(\mathrm{U}^{4+}\right)$ under oxic conditions and this is in accordance with the literature reports. Captivating the advantage of these available active sites in NNRG with a high surface, easy to synthesize, low cost and the use of biodegradable polymeric backbone could further help in developing a sustainable approach for scaling up and use as an efficient scavenger for $U$ from effluents of nuclear and mining industries. Further, it can be extended for extraction of uranium from seawater, as adsorption remains unaffected over a broad $\mathrm{pH}$ range.

\section{ASSOCIATED CONTENT}

\section{Supporting information available:}

Material, methods, synthesis, experimental conditions and other characterization details are provided in the supporting information.

\section{Conflicts of interest}

The authors declare no conflict of interest.

\section{Acknowledgements}

This work was supported by SERB research grants (S.K., SERB SB/FT/CS-072/2014). AD acknowledges SERB grants (EMR/2016/001850 \& JCB/2017/000004) for financial support. The authors acknowledge the technical support from the CSIRNCL, Pune and CSIR-CSMCRI, Bhavnagar. S.K. is thankful to Dr. Ketan Patel, and Dr. Santanu Karan for their contribution during scientific discussions. A PRIS number (CSIR-CSMCRI-51/2020) has been assigned for this manuscript. 


\section{Notes and references}

[1] A Joint Report by the Nuclear Energy Agency and the International Atomic Energy Agency (2018). Uranium 2018: Resources, Production and Demand. OECD 2018, NEA No. 7413.

[2] William, H. Environmental Critiques of Nuclear Energy. Pomona Senior Theses 2012, Paper 58 and references within.

[3] Spencer, J.; Loris, N. D. Three Mile Island and Chernobyl: What Went Wrong and Why Today's Reactors Are Safe. The Heritage Foundation 2009, 2367, 1-4.

[4] Steinhauser, G. Fukushima's Forgotten Radionuclides: A Review of the Understudied Radioactive Emissions. Environ. Sci. Technol. 2014, 48, 4649-4663.

[5] Abney, C.W.; Mayes, R.T.; Saito, T.; Dai, S. Materials for the Recovery of Uranium from Seawater. Chem. Rev. 2017, 117, 13935-14013.

[6] Wang, L.; Yuan, L.; Chen, K.; Zhang, Y.; Deng, Q.; Du, S.; Huang, Q.; Zheng, L.; Zhang, J.; Chai, Z.; Barsoum, M.W.; Wang, X.; Shi, W. Loading Actinides in Multilayered Structures for Nuclear Waste Treatment: The First Case Study of Uranium Capture with Vanadium Carbide MXene. ACS Appl. Mater. Interfaces 2016, 8, 16396-16403.

[7] Su, S.; Liu, Q.; Liu, J.; Zhang, H.; Li, R.; Jing, X.; Wang, J. Functionalized Sugarcane Bagasse for U(VI) Adsorption from Acid and Alkaline Conditions. Scientific Reports 2018, 8, 793.

[8] Bai, Z.; Yuan, L.; Zhu, I.; Liu, Z.; Chu, S.; Zheng, L.; Zhang, J.; Chai, Z.; Shi, W. Introduction of amino groups into acid-resistant MOFs for enhanced U(vi) sorption. J. Mater. Chem. A 2015, 3, 525-534.

[9] Zhang, W.; Ye, G.; Chen, J. Novel mesoporous silicas bearing phosphine oxide ligands with different alkyl chains for the binding of uranium in strong $\mathrm{HNO} 3$ media. J. Mater. Chem. A 2013, 1, 12706-12709.

[10] Vicente, L. V.; Quiros, Y.; Barriocanal, F. P.; Novoa, J. M. L.; Hernandez, F. J. L.; Morales, A. I. Nephrotoxicity of Uranium: Pathophysiological, Diagnostic and Therapeutic Perspectives. Toxicol. Sci. 2010, 118, 324-347.

[11] Kurttio, P.; Komulainen, H.; Leino, A.; Salonen, L.; Auvinen, A.; Saha, H. Bone as a possible target of chemical toxicity of natural uranium in drinking water. Environ. Health Persp. 2004 $113,68-72$.

[12] Clark, D. L.; Hobart, D. E.; Ned, M. P. Actinide Carbonate Complexes and Their Importance in Actinide Environmental Chemistry. Chem. Rev. 1995, 95, 25-48.

[13] Wang, J.; Zhuang, S. Extraction and adsorption of U(VI) from aqueous solution using affinity ligand-based technologies: an overview. Rev. Environ. Sci. Biotechnol. 2019, 18, 437-452.

[14] Lumetta, G. J.; Gelis, A. V.; Carter, J. C.; Niver, C. M.; Smoot, M. R. Solvent Extr. Ion Exc. 2014, 32, 333-347.

[15] Ansari, S. A.; Pathak, P.; Mohapatra, P. K.; Manchanda, V. K. Chemistry of Diglycolamides: Promising Extractants for Actinide Partitioning. Chem. Rev. 2012, 112, 1751.

[16] Zhang, H.; Liu, W.; Li, A.; Zhang, D.; Li, X.; Zhai, F.; Chen, L.; Chen, L.; Wang, Y.; Wang, S. Three Mechanisms in One Material: Uranium Capture by a Polyoxometalate-Organic Framework through Combined Complexation, Chemical Reduction, and Photocatalytic Reduction. Angew. Chem. Int. Ed. 2019, 58, 16110-16114.

[17] Huynh, J.; Palacio, R.; Safizadeh, F.; Lefevre, G.; Descostes, M.; Eloy, L.; Guignard, N.; Rousseau, J.; Royer, S.; Tertre, E.; Batonneau-Gener, I. Adsorption of Uranium over NH2Functionalized Ordered Silica in Aqueous Solutions. ACS Appl. Mater. Interfaces 2017, 9, 15672-15684.

[18] Asiabi, H.; Yamini, Y.; Shamsayei, M. Highly efficient capture and recovery of uranium by reusable layered double hydroxide intercalated with 2-mercaptoethane sulfonate. Chem. Eng. J. 2018, 337, 609.

[19] Feng, M. L.; Sarma, D.; Qi, X. H.; Du, K. Z.; Huang, X. Y.; Kanatzidis, M. G. Efficient Removal and Recovery of Uranium by a Layered Organic-Inorganic Hybrid Thiostannate. J. Am. Chem. Soc. 2016. 138, 12578-12585.

[20] Wang, Z.; Xu, C.; Lu, Y.; Wu, F.; Ye, G.; Wei, G.; Sun, T.; Chen, J. Visualization of Adsorption: Luminescent Mesoporous SilicaCarbon Dots Composite for Rapid and Selective Removal of $\mathrm{U}(\mathrm{VI})$ and in Situ Monitoring the Adsorption Behavior. ACS Appl. Mater. Interfaces 2017, 9 (8), 7392-7398.

[21] Yang, S.; Qian, J.; Kuang, L.; Hua, D. Ion-Imprinted Mesoporous Silica for Selective Removal of Uranium from Highly Acidic and Radioactive Effluent. ACS Appl. Mater. Interfaces 2017, 9(34), 29337-29344.

[22] Gupta, N. K.; Sengupta, A.; Gupta, A.; Sonawane, J. R.; Sahoo, H. Bio sorption-an alternative method for nuclear waste management: A critical review. J. Environ. Chem. Eng. 2018, 6, 2159-2175.

[23] Bhalara, P. D.; Punetha, D.; Balasubramanian, K. A review of potential remediation techniques for uranium $(\mathrm{VI})$ ion retrieval from contaminated aqueous environment. J. Environ. Chem. Eng. 2014, 2(3), 1621-1634.

[24] Fu, J.; Chen, L.; Lia, J.; Zhang, Z. Current status and challenges of ion imprinting. J. Mater. Chem. A 2015, 3, 1359813627.

[25] Das, S.; Oyola, Y.; Mayes, R. T.; Janke, C. J.; Kuo, L. J.; Gill, G.; Wood, J. R.; Dai, S. Extracting uranium from seawater: Promising AF series adsorbents. Ind. Eng. Chem. Res. 2016, 55, 4110-4117.

[26] Das, S.; Oyola, Y.; Mayes, R. T.; Janke, C. J.; Kuo, L. J.; Gill, G.; Wood, J. R.; Dai, S. Extracting Uranium from Seawater: Promising Al Series Adsorbents. Ind. Eng. Chem. Res. 2016, 55, 4103-4109.

[27] Yuan, Y.; Yang, Y.; Ma, X.; Meng, Q.; Wang, L.; Zhao, S.; Zhu, G. Molecularly Imprinted Porous Aromatic Frameworks and Their Composite Components for Selective Extraction of Uranium lons. Adv. Mater. 2018, 30, 1706507.

[28] Sun, Q.; Aguila, B.; Earl, L. D.; Abney, C. W.; Wojtas, L.; Thallapally, P. K.; Ma, S. Covalent Organic Frameworks as a Decorating Platform for Utilization and Affinity Enhancement of Chelating Sites for Radionuclide Sequestration. Adv. Mater. 2018, 30, 1705479.

[29] Mayes, R. T.; Gorka, J.; Dai, S. Impact of Pore Size on the Sorption of Uranyl under Seawater Conditions. Ind. Eng. Chem. Res. 2016, 55, 4339-4343.

[30] Sun, Y.; Wu, Z.; Wang, X.; Ding, C.; Cheng, W.; Yu, S.; Wang, $X$. Macroscopic and microscopic investigation of $U(V I)$ and $\mathrm{Eu}(\mathrm{III})$ adsorption on carbonaceous nanofibers. Environ. Sci. Technol. 2016, 50 (8), 4459-4467.

[31] Song, Y.; Wei, G.; Kopec, M.; Rao, L.; Zhang, Z.; Gottlieb, E.; Wang, Z.; Yuan, R.; Ye, G.; Wang, J.; Kowalewski, T.; Matyjaszewski, K. Copolymer-Templated Synthesis of NitrogenDoped Mesoporous Carbons for Enhanced Adsorption of Hexavalent Chromium and Uranium. ACS Appl. Nano Mater. 2018, 1 (6), 2536-2543.

[32] Wang, M.; Qiu, J.; Tao, X.; Wu, C.; Cui, W.; Liu, Q.; Lu, S. Effect of $\mathrm{pH}$ and lonic Strength on U(IV) Sorption to Oxidized Multiwalled Carbon Nanotubes. Radioanal. Nucl. Chem. 2011, 288, 895-901.

[33] Chen, H. J.; Chen, Z.; Zhao, G. X.; Zhang, Z. B.; Xu, C.; Liu, Y. H.; Chen, J.; Zhuang, L.; Haya, T.; Wang, X. K. Enhanced Adsorption of $\mathrm{U}(\mathrm{VI})$ and 241Am(III) from Wastewater Using $\mathrm{Ca} / \mathrm{Al}$ Layered Double Hydroxide@Carbon Nanotube Composites. J. Hazard. Mater. 2018, 347, 66-77.

[34] Chen, H.; Zhang, Z.; Wang, X.; Chen, J.; Xu, C.; Liu, Y.; Yu, Z.; Wang, X. Fabrication of Magnetic Fe/Zn Layered Double Oxide@Carbon Nanotube Composites and Their Application for $\mathrm{U}(\mathrm{VI})$ and 241Am(III) Removal. ACS Appl. Nano Mater. 2018, 1 (5), 2386-2396.

[35] Li, W.; Troyer, L. D.; Lee, S. S.; Wu, J.; Kim, C.; Lafferty, B. J.; Catalano, J. G.; Fortner, J. D. ACS Appl. Mater. Interfaces 2017, 9 (15), 13163-13172. 
[36] Li, D.; Egodawatte, S.; Kaplan, D. I.; Larsen, S. C.; Serkiz, S. M.; Seaman, J. C.; Scheckel, K. G.; Lin, J.; Pan, Y. Sequestration of $\mathrm{U}(\mathrm{VI})$ from Acidic, Alkaline, and High lonic-Strength Aqueous Media by Functionalized Magnetic Mesoporous Silica Nanoparticles: Capacity and Binding Mechanisms. Environ. Sci. Technol. 2017, 51 (24), 14330-14341.

[37] Xu, M.; Han, X.; Hua, D. Polyoxime-functionalized magnetic nanoparticles for uranium adsorption with high selectivity over vanadium. J. Mater. Chem. A 2017, 5, 12278-12284.

[38] Cali, E.; Qi, J.; Preedy, O.; Chen, S.; Boldrin, D.; Branford, W. R.; Vandeperre, L.; Ryan, M. P. Functionalised magnetic nanoparticles for uranium adsorption with ultra-high capacity and selectivity. J. Mater. Chem. A 2018, 6, 3063-3073.

[39] Sun, Y.; Shao, D.; Chen, C.; Yang, S.; Wang, X. Highly Efficient Enrichment of Radionuclides on Graphene Oxide Supported Polyaniline. Environ. Sci. Technol. 2013, 47, 9904-9910.

[40] Yuan, Y.; Yu, Q.; Wen, J.; Li, C.; Guo, Z.; Wang, X.; Wang, X. Ultrafast and Highly Selective Uranium Extraction from Seawater by Hydrogel-like Spidroin-based Protein Fiber. Angew. Chem. Int. Ed. 2019, 58, 11785-11790.

[41] Kou, S.; Yang, Z.; Sun, F. Protein Hydrogel Microbeads for Selective Uranium Mining from Seawater. ACS Appl. Mater. Interfaces 2017, 9, 2035-2039.

[42] Zhao, S.; Yuan, Y.; Yu, Q.; Niu, B.; Liao, J.; Guo, Z.; Wang, N. A Dual-Surface Amidoximated Halloysite Nanotube for HighEfficiency Economical Uranium Extraction from Seawater. Angew. Chem. Int. Ed. 2019, 58, 14979-14985.

[43] Yuan, Y.; Niu, B.; Yu, Q.; Guo, X.; Guo, Z.; Wen, J.; Liu, T.; Zhang, H.; Wang, N. Photoinduced Multiple Effects to Enhance Uranium Extraction from Natural Seawater by Black Phosphorus Nanosheets. Angew. Chem. Int. Ed. 2019, 58, 1-9.

[44] Yu, J.; Liao, H.; Zhu, W.; Duan, T.; Wang, S.; Kuang, M.; Zhang, Y.; Lin, X.; Luo, X.; Zhou, J. Marinobacter sp. Stable Hydrous Titanium Oxide-Functionalized Bovine Serum Albumin Nanospheres for Uranium Capture from Spiked Seawater. ACS Appl. Mater. Interfaces 2019, 11, 40898-40908.

[45] Yuan, Y.; Zhao, S.; Wen, J.; Wang, D.; Guo, X.; Xu, L. Wang, X.; Wang, N. Rational Design of Porous Nanofiber Adsorbent by Blow-Spinning with Ultrahigh Uranium Recovery Capacity from Seawater. Adv. Funct. Mater. 2019, 29, 1805380.

[46] Sun, Q.; Aguila, B.; Perman, J.; Ivanov, A. S.; Bryantsev, V. S.; Earl, L. D.; Abney, C. W.; Wojtas, Y.; Ma, S. Bio-inspired nanotraps for uranium extraction from seawater and recovery from nuclear waste. Nat. Commun. 2018, 9, 1644.

[47] Zhang, M.; Li, Y.; Bai, C.; Guo, X.; Han, J.; Hu, S.; Jiang, H.; Tan, W.; Li, S.; Ma, L. Synthesis of Microporous Covalent Phosphazene-Based Frameworks for Selective Separation of Uranium in Highly Acidic Media Based on Size-Matching Effect. ACS Appl. Mater. Interfaces 2018, 10, 28936-28947.

[48] Budnyak, T. M.; Plaska, A. G.; Strizhak, A. V.; Sternik, D.; Komarov, I. V.; Majdan, M.; Tertykh, V. A. Imidazole-2ylPhosphonic Acid Derivative Grafted onto Mesoporous Silica Surface as a Novel Highly Effective Sorbent for Uranium(VI) Ion Extraction. ACS Appl. Mater. Interfaces 2018, 10, 6681-6693.

[49] Shi, S.; Qian, Y.; Mei, P.; Yuan, Y.; Jia, N.; Dong, M.; Fan, J.; Guo, Z.; Wang, N. Robust flexible poly(amidoxime) porous network membranes for highly efficient uranium extraction from seawater. Nano Energy 2020, 71, 104629.

[50] Zhao, X.; Zhang, D.; Yu, R.; Chen, S.; Zhao, D. Tetrahydrosalen Uranyl(VI) Complexes: Crystal Structures and Solution Binding Study. Eur. J. Inorg. Chem. 2018, 1185-1191.

[51] Faizova, R.; Scopelliti, R.; Chauvin, A. S.; Mazzanti, M. Synthesis and Characterization of a Water Stable Uranyl(V) Complex. J. Am. Chem. Soc. 2018, 140, 13554-13557.

[52] Tondreau, A. M.; Duignan, T. J.; Stein, B. W.; Fleischauer, V. E.; Autschbach, J.; Batista, E. R.; Boncella, J. M.; Ferrier, M. G.; Kozimor, S. A.; Mocko, V.; Neidig, M. L.; Cary, S. K.; Yang, P. A Pseudotetrahedral Uranium(V) Complex. Inorg. Chem. 2018, 57, 8106-8115.
[53] Coughlin, E. J.; Qiao, Y.; Lapsheva, E.; Zeller, M.; Schelter, E. J.; Bart, S. C. Uranyl Functionalization Mediated by Redox-Active Ligands: Generation of O-C Bonds via Acylation. J. Am. Chem. Soc. 2019, 141, 1016-1026.

[54] Ivanov, A. S.; Parker, B. F.; Zhang, Z.; Aguila, B.; Sun, Q.; Ma, S.; Popova, S. J.; Arnold, J.; Mayes, R. T.; Dai, S.; Bryantsev, V. S.; Rao, L.; Popovs, I. Siderophore-inspired chelator hijacks uranium from aqueous medium. Nature Comm. 2019, 10, 819.

[55] Sockwell, A. K.; Wetzler. M. Beyond Biological Chelation: Coordination of f-Block Elements by Polyhydroxamate Ligands. Chem. Eur. J. 2019, 25, 2380-2388.

[56] Li, J.; Wang, X. X.; Zhao, G. X.; Chen, C. L.; Chai, Z. F.; Alsaedi, A.; Hayat, T.; Wang, X. K. Metal-organic framework-based materials: superior adsorbents for the capture of toxic and radioactive metal ions. Chem. Soc. Rev. 2018, 47, 2322-2356.

[57] Tripathi, A.; Melo, J. S. Synthesis of a low-density biopolymeric chitosan-agarose cryomatrix and its surface functionalization with bio-transformed melanin for the enhanced recovery of uranium(vi) from aqueous subsurfaces. RSC Adv. 2016, 6, 37067-37078.

[58] Tripathi, A.; Melo, J. S. Self-assembled biogenic melanin modulated surface chemistry of biopolymers-colloidal silica composite porous matrix for the recovery of uranium. J. Appl. Polym. Sci. 2019, 136, 46937.

[59] Kushwaha, S.; Sreedhar, B.; Padmaja, P. XPS, EXAFS, and FTIR As Tools To Probe the Unexpected Adsorption-Coupled Reduction of $\mathrm{U}(\mathrm{VI})$ to $\mathrm{U}(\mathrm{V})$ and $\mathrm{U}(\mathrm{IV})$ on Borassus flabelliferBased Adsorbents. Langmuir 2012, 28, 16038-16048.

[60] Xu, X.; Zhang, H.; Ao, J.; Xu, L.; Liu, X.; Guo, X.; Li, J.; Zhang, L.; Li, Q.; Zhao, X.; Ye, B.; Wang, D.; Shen, F.; Ma, H. 3D hierarchical porous amidoxime fibers speed up uranium extraction from seawater. Energy Environ. Sci. 2019, 12, 19791989.

[61] Silverstein, R.M.; Bassler, G.C.; and Morrill, T.C. Spectrometric Identification of Organic Compounds. $4^{\text {th }}$ ed. New York: John Wiley and Sons, 1981.

[62] Siddhanta, A. K.; Meena, R.; Prasad, G; Chhatbar, M.U.; Mehta, G.K.; Oza, M.D.; Kumar, S.; Prasad, K. Carbohydrate Polymers: Development, Properties and Applications, NOVA Science, New York, 2010.

[63] Saha, S.; Chhatbar, M.U.; Mahato, P.; Praveen, L.; Siddhanta, A.K.; Das, A. Rhodamine-alginate conjugate as self indicating gel beads for efficient detection and scavenging of $\mathrm{Hg}^{2+}$ and $\mathrm{Cr}^{3+}$ in aqueous media. Chem. Commun. 2012, 48, 1659-1661.

[64] Kushwaha, S.; Sreedhar, B.; Bhatt, R.; Sudhakar. P. P. Spectroscopic characterization for remediation of copper, cadmium and mercury using modified palm shell powder. $J$. Taiwan Inst. Chem. Eng. 2015, 46, 191-199.

[65] Kushwaha, S.; Soni, H.; Ageetha, V.; Padmaja, P. An insight into the production, characterization, and mechanisms of action of low-cost adsorbents for removal of organics from aqueous solution. Crit. Rev. Environ. Sci. Technol. 2013, 43 (5), 443-549.

[66] Kushwaha, S.; Marcus, A. K.; Rittmann, B. E. pH-dependent speciation and hydrogen $\left(\mathrm{H}_{2}\right)$ control $\mathrm{U}(\mathrm{VI})$ respiration by Desulfovibrio Vulgaris. Biotechnol. Bioeng. 2018, 115, 14651474.

[67] Kushwaha, S.; Sreedhar, B.; Padmaja, P. A spectroscopic study for understanding the speciation of $\mathrm{Cr}$ on palm shell based adsorbents and their application for the remediation of chrome plating effluents. Biores. Technol. 2012, 116, 15-23.

[68] Kushwaha, S.; Sreedhar, B.; Padmaja, P. Adsorption of $\mathrm{Hg}^{2+}$ onto Borassus Flabellifer: A redox mechanism. Chem. Eng. J 2012, 193, 328-338.

[69] Kushwaha, S.; Sudhakar, P. P. Sorption of uranium from aqueous solutions using palm-shell-based adsorbents: a kinetic and equilibrium study. J. Environ. Rad. 2013, 126, 115-124.

[70] Kumar, K.V.; Gadipelli, S.; Wood, B.; Ramisetty, K.A.; Stewart, A.A.; Howard, C.A.; Brett, D.J.L.; Rodriguez-Reinoso, F. Characterization of the adsorption site energies and 
heterogeneous surfaces of porous materials. J. Mater. Chem. A, 2019, 7, 10104.

[71] Xiao, Y.; Azaiez, J.; Hill, J.M. Erroneous Application of Pseudo-Second-Order Adsorption Kinetics Model: Ignored Assumptions and Spurious Correlations. Ind. Eng. Chem. Res. 2018, 57, 2705-2709.

[72] Vijayaraghavan, K.; Palanivelu, K.; Velan, M. Biosorption of copper(II) and cobalt(II) from aqueous solutions by crab shell particles. Biores. Technol. 2006, 97, 1411-1419.

[73] Reddad, Z.; Gerente, C.; Andres, Y.; Cloirec, P.L.; Adsorption of several metal ions onto a low-cost biosorbent: kinetic and equilibrium studies. Environ. Sci. Technol. 2002, 36, 2067-2073.

[74] Febrianto, J.; Kosasih, A.N.; Sunarso, J.; Ju, Y.H.; Indraswati, N.; Ismadji, S. Equilibrium and kinetic studies in adsorption of heavy metals using biosorbent: a summary of recent studies. $J$. Hazard. Mater. 2009, 162, 616-645.

[75] Preetha, C.; Gladis, J. M.; Rao, T. P. Removal of Toxic Uranium from Synthetic Nuclear Power Reactor Effluents Using Uranyl Ion Imprinted Polymer Particles. Environ. Sci. Technol. 2006, 40, 3070-3074.

[76] Hashem, E.; Swinburne, A. N.; Schulzke, C.; Evans, R. C.; Platts, J. A.; Kerridge, A.; Natrajan, L. S.; Baker, R. J. Emission spectroscopy of uranium(IV) compounds: a combined synthetic, spectroscopic and computational study. RSC Adv. 2013, 3, 43504361. 


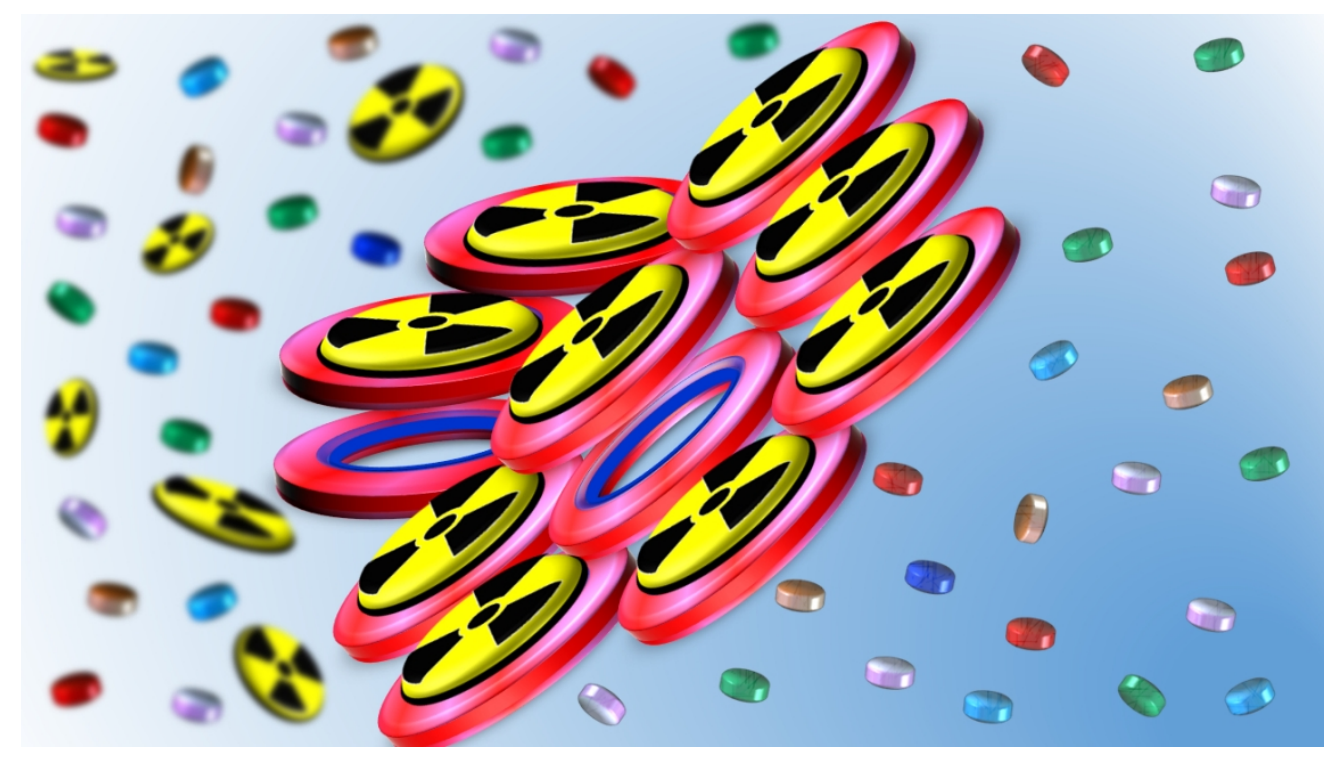

Polymer nano rings for selective recovery of Uranium $338 \times 190 \mathrm{~mm}(96 \times 96 \mathrm{DPI})$ 